\title{
PERCEPTION OF A MULTIDISCIPLINARY TEAM ON PHYSICAL RESTRAINT USE ON OLDER ADULTS: CARE PARADOXES
}

\author{
Percepção da equipe multiprofissional sobre a \\ contenção mecânica de idosos: paradoxos do cuidado
}

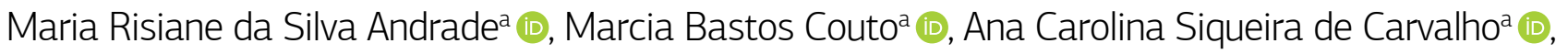 \\ Patricia de Fatima Augusto Barros ${ }^{\mathrm{a}}\left(\mathbb{D}\right.$, Romulo DelValle ${ }^{\mathrm{a}}$ (1), Rosimere Ferreira Santana ${ }^{\mathrm{a}}$ (1)
}

OBJECTIVE: To describe the perception of a multidisciplinary team on the use of physical restraint in older adults. METHODS: Qualitative research conducted with 58 health professionals in two long term care facilities for older adults located in the state of Rio de Janeiro, Brazil. Semi-structured interviews were further analyzed using thematic content analysis. The data was collected from November 2017 to June 2018. RESULTS: Twenty-one initial codes were identified and organized in three categories: team perception of the consequences and risks of a physical restraint (the patient's safety paradox); implications of the decision of physical restraint of the older adults; and strategies to restrain and not restrain. CONCLUSIONS: The results reinforce the need for training of professionals on restraint-free alternatives of care, as part promoting a culture of care that respects the right to freedom and the dignity of people - especially the most vulnerable ones.

KEYWORDS: restraint, physical; homes for the aged; aged; geriatric nursing; health of the older adults.

OBJETIVO: Descrever a percepção da equipe multiprofissional sobre o uso da contenção mecânica em idosos. METODOLOGIA: Pesquisa qualitativa realizada com 58 profissionais da área da saúde em duas Instituições de Longa Permanência para Idosos localizadas no estado do Rio de Janeiro, Brasil. Utilizou-se entrevista semiestruturada, com análise temática do conteúdo. O O período de coleta de dados foi de novembro de 2017 a junho de 2018. RESULTADOS: Foram identificadas 21 unidades de registro, organizadas em três categorias: percepção da equipe sobre as consequências e riscos do uso da contenção mecânica: o paradoxo da segurança do paciente; implicações na decisão da contenção mecânica de idosos; e estratégias para conter e não conter. CONCLUSÕES: Os achados refletem a necessidade de capacitação dos profissionais no que tange às estratégias de cuidado alternativas, livres de contenção, como parte da promoção de uma cultura de cuidado que respeite o direito à liberdade e a dignidade das pessoas, especialmente as mais vulneráveis.

PALAVRAS-CHAVE: restrição física; instituição de longa permanência para idosos; idoso; enfermagem geriátrica; saúde do idoso.

aniversidade Federal Fluminense - Niterói (RJ), Brazil.

Correspondence data

Ana Carolina Siqueira de Carvalho - Rua Dr. Celestino, 74 - Centro - CEP: 24020091 - Niterói (RJ), Brazil. E-mail: siqueiraana@id.uff.br Received on: 05/17/2020. Accepted on: 06/27/2020

https://doi.org/10.5327/Z2447-212320202000057 


\section{INTRODUCTION}

Long-term care facilities for older adults (LTCF) are units for long-term care with a residential character, intended as a collective home for people aged 60 or over, with or without family support, and which may or may not be linked to the governmental initiative. ${ }^{1}$

Health professionals from different areas and with different training work at these places, specializing in Gerontology or general hospital training, as well as professional caregivers, who are the majority of the current LTCF workforce. ${ }^{2}$ Thus, a multiprofessional approach is needed to meet the complexity of care that the older adults population - mostly dependent - require in this care modality. ${ }^{2}$

Although a physical restraint is controversial, its use in care environments, especially at LTCFs, is routinely based on the argument of patient safety: prevention of falls, control of patients with challenging behaviors and walking, prevention of physical damage that patients may cause to themselves or others, and a means of continuing medical treatments without the patient's knowledge. ${ }^{3,4}$

There are four types of restraint: physical, mechanical, pharmacological, chemical and environmental. The physical type involves an individual using his own body to contain a patient; the environmental type restricts a person's exit from a certain space; chemical or pharmacological restraint involves drugs aimed at reducing motor activity (with no therapeutic purposes); and the mechanical type is related to the use of equipment to immobilize the individual, including a seat belt on a chair or bed, chair with table, wrist and ankle immobilizers, side rails, geriatric reclining seats with seat belt, bandages or gauze. ${ }^{5}$

Recent data estimates a prevalence of $7.45 \%$ of mechanical restraint use in the LTCFs of the state of Rio de Janeiro, with a forecast error of $2.45 \%$ in the $95 \%$ confidence interval. ${ }^{3} \mathrm{~A}$ recent integrative review reported a prevalence of mechanical restraint in LTCFs between 4 and 85\%, and the profile of patients exposed to it was usually the older adults with functional disabilities, high dependence for activities of daily living, mobility problems, cognitive disorders, behavior problems, and multiple falls.,

It is important to clarify that restraint use is also responsible for adverse events such as incontinence, delirium worsening, damage related to immobilization such as pressure ulcers, decline in cognition, among others - not excluding obit. ${ }^{5}$ In a study conducted in Germany, 22 cases of death from asphyxiation caused by restraint were analyzed. Three people had been hung upside down, eight had died from chest compression and 11 from strangulation. ${ }^{7}$ As a conclusion, the study recommends using all possible alternative methods of restraint to prevent deaths and constant monitoring if there is no other viable approach. ${ }^{7}$
The difficult professional decision to use or not physical restraint is known to cause psychological and emotional discomfort in professionals. ${ }^{3}$ In addition, the type of bond between the health professional and the older adults has an impact on this decision, as well as their education, religion, age, sex, years of experience, and work regimen at the LTCF. ${ }^{8}$

The use of mechanical restraint is related to negative adverse effects and, based on this premise, the objective of this study is to describe the perception of the multidisciplinary team about mechanical restraint applied to the older adults.

On account of the Brazilian scenario - scarce in scientific productions discussing the use of mechanical restraint - this study intends to recommend the training of LTCF health professionals for a culture of care free from restraints. This is something urgent, considering the increase in population aging. Our study contributes to a critical reflection on the actions taken in the absence of scientific evidence to support care practices.

\section{METHODS}

This was a qualitative research, based on a semi-structured interview with thematic content analysis, using the method of Lawrence Bardin. The participants were professionals who worked directly in the provision of care to the older adults residents of two LTCF located in the state of Rio de Janeiro, Brazil: a non-profit, philanthropic facility, and a for-profit facility.

The interviewers, two authors of the present article, were responsible for the interviews during their postgraduate extension in Gerontology. Both are nurses who worked at the LTCFs selected for the study. They presented the objective of the research to all professionals in the facilities and these, spontaneously, decided to participate or not in the research.

The first institution has 183 members, 45 of which are dedicated to providing care. Among them, 43 agreed to participate in the investigation: four physicians, two physical therapists, a nutritionist, a nurse, 24 caregivers for the older adults, 11 nursing technicians. Only two nursing technicians were unable to participate in the study.

The second institution was composed of 24 members, 17 of whom were directly dedicated to care. From these, 15 agreed to participate in the study, namely: a nurse, six nursing technicians, four caregivers for the older adults, a social worker, a psychologist, a physical therapist, a nutritionist.

In total, 58 employees (43 from the first institution and 15 from the second) agreed to take part in the research and only four refused, claiming they were not interested in the topic.

Data was collected from November 2017 to June 2018, with the use of semi-structured interview with four questions: 
how do you perceive restraint? What are the most common types of restraint in your practice? Why would you indicate restraint? What risks do you believe are related to restraint?

The interviews were previously scheduled and took place at the units, according to professionals' availability, in a quiet environment reserved for the researcher and the participant. The audio recordings of the interviews lasted, on average, 13 to 15 minutes and generated 21 pages of data. No repeated interviews were conducted. The interviewers' bond with participants was strictly professional. During the sessions, they introduced themselves to the participants as researchers, clarifying the scientific objective related to the use of mechanical restraint in LTCFs.

During and after the interviews, field notes were made on particularities and characterization of the facilities, as well as important aspects observed.

After data collection, the testimonies were transcribed and typed in full by the interviewer herself (and these were not returned to the participants for further comments and correction), and then submitted to content thematic analysis, with successive detailed readings to allow codification.

The common themes were identified, grouped into categories and progressively regrouped into new sub-categories. The criterion used for characterization was semantical, according to which all themes with the same meaning were grouped in the same category. The rules for selecting the corpus by Lawrence Bardin were observed: mutual exclusion, homogeneity, relevance, objectivity and fidelity, and productivity. Finally, the corpus was classified into three categories: team's perception of the consequences and risks of mechanical restraint (the patient's safety paradox); implications for the decision of mechanical restraint of the older adults; strategies to contain and not contain.

All participants who agreed to contribute spontaneously to the study authorized the recording of the interviews by signing the free and informed consent form in person and in a reserved place (in the presence of only one of the researchers), in their own work place (LTCF).

The study was approved by the Research Ethics Committee on April 5, 2017 and complied with Resolution 466/12 by the National Research Ethics Commission (CONEP), under opinion 2,003,054.

\section{RESULTS}

\section{Characterizing scenarios and participants}

First scenario

The LTCF is located in an architectural complex that includes a religious convent and a hospital. The LTCF itself is composed of two non-linear building constructions, with internal elevators and ramps for external access. The wings and floors are subdivided according to the degree of dependence of the nuns. The first facility was built in mid-19th century, and the second in the 21 st century. The residents' rooms are individual, with private bathrooms, and some basic adaptations for dependent people. The long-term care complex comprises gardens, chapels, nursing stations, dental, nutrition and physical therapy offices, pharmacy, laundry room, and spaces for various activities.

The hospital attached to this LTCF offers supportive care to older adults residents whenever necessary, with the transfer of clinically unstable cases or total dependence cases. Currently, the LTCF services 70 older adults women, with a minimum age of 69 years and a maximum age of 103 years (mean 79.70 years). They are women who, throughout their lives, exercised their activities mainly as teachers, nurses, and social workers. All nuns are Brazilian, with higher education, and who speak other languages, mainly French; 46\% are independent for all activities of daily living, $48 \%$ are partially dependent, and $4 \%$ are totally dependent. Among the most common diagnoses, one can mention depression, which affects $31 \%$ of residents, and dementia, which affects $24 \%$ of them. It is noteworthy that $2 \%$ of patients present recurrent behavioral disorders such as: delirium, psychomotor agitation, catastrophic reaction, and perceptual disorders.

The LTCF had an internal team composed of coordination activities, management service performed by religious women of the same order, and care services performed by an outsourced multidisciplinary team. Among research participants, five members had a specialized training in Geriatrics or Gerontology, and for that reason they often receive graduate trainees in Gerontology. Teams have a low turnover of professionals, and most members have worked at the institution for more than three years. All members of the health team are females with mean age of 47.25 years.

\section{Second scenario}

The second scenario was a private hospital for seniors located in the city of Niterói, with 26 beds. The long-term care unit is made up of two residential buildings. The front building holds: three collective bedrooms, two bathrooms, a large living room, balcony, laundry room, kitchen, coordination room, and area for activities. The back building has: two rooms, three small rooms, two bathrooms, basic adaptations for dependents, access ramp and stairs. Altogether, the institution serves 23 older people, with a minimum age of 74 years and a maximum of 97 years (mean age 86.70 years). Most residents are females and with some degree of dependence (partial or 
total); $80 \%$ of residents are diagnosed with diseases of the circulatory system, $10 \%$ suffer from dementia, and only $1 \%$ have behavioral disorders.

The participants of the second LTCF aged 40 years old on average, most of whom were women, hired without employment bond.

At the end of interview interpretation, 21 initial codes were identified and organized into three categories: the team's perception of the consequences and risks of mechanical restrain (the patient's safety paradox); implications for the decision of mechanical restraint of the older adults; strategies to "contain and not contain". The categories are listed moving forward.

\section{Category I: team's perception of the consequences and risks of mechanical restraint: the patient safety paradox}

In this category, speeches on the use of mechanical restraint as a justification for the prevention of falls and patient safety are highlighted: "For the safety of the older adults, because we are sometimes bathing them and, at that moment we are absent, we use the band as a safety measure (Caregiver I1); "Because it is best to protect from a fall than to have them fall and face a worse situation" (Nursing technician I2); "It is not the best resource for dealing with unrest. But it is often what we have, and also makes agitation worse. It has a paradoxical effect"(Physician I1).

The team has shown knowledge about the adverse events of mechanical restraint as cited in the literature: "Pressure injuries, hypostatic pneumonia, urinary retention, several other negative factors" (Nursing technician I1); "It can cause wounds, especially in the upper limbs, in the abdominal region, it can cause vomiting, hanging." (Nursing technician I1); "Delirium, dehydration, malnutrition. Restraint causes several damages, especially patient neglect: they are apparently safe, so they're not monitored and often forgotten"(Physician I1); "Restraint puts limits to the older adults [...\}, it is horrible, it is not nice, it can lead to bronchoaspiration [...], and the worsening of behavioral disorders" (Nursing technician I1).

The multiprofessional team also mentioned in details the morbidity risks of using restraint in dependent older people: "If the restraint is too tight, they will be more agitated, they will feel discomfort. They will insist on getting out of it. At that moment, they may end up falling" (Caregiver I2); "Several risks [...], including falls. They are human beings that just aged! From the moment they feel trapped [...], they will be stressed, stress leads to anxiety, and they end up getting hurt" (Caregiver I1); "Edema. If restraint in the arms is too tight, it can hurt. Especially the region of the wrist, abdomen, it can cause injuries depending on the pressure applied. It is unpleasant, it is sad" (Caregiver I1).
Thus, despite the team's knowledge of the risks, consequences, adverse events and risk of morbidity of mechanical restraint, professionals and caregivers maintain it, paradoxically, finding ground in the patient safety argument and prevention of falls.

\section{Category II: implications for the decision of mechanical restraint in the older adults}

In this category, speeches were about what is implicated in the decision of mechanical restraint: professional training, scarcity of human resources, knowledge of other forms of restraint, and established concept of restraint: "As a physical therapist, I do not use restraint techniques. Any type of restraint" (Physical therapist I2); "In my practice of nutrition, we may need hand restraint, and we use the gloves, so that the older person does not remove the nasogastric tube"(Nutritionist I1); "In my practice as a physician, we use chemical restraint, especially in patients who are at home" (Physician I1); "In my professional practice, I do not work with restraint [...], I do not advise on the restraint procedure, my category does not indicate restraint, it will be indicated by the doctor or by the nurse" (Social Worker I2); "This is a well-discussed and complex topic to be addressed, and there are protocols that guide physical restraint" (Nurse I1); "We have mixed feelings. Even against our will, this is the decision, I have to use restraint" (Nursing technician I2);

The lack of employees, depending on the location. The environment that does not favor well-being, so that we can leave them free knowing that nothing will happen to them. We leave them free without offering any safety, and it also serves to keep me calm. That, if this is my job, I can't leave them by themselves, I have to take care of them in every way, even protect them from themselves (Nursing Technician I1).

The use of restraint translates as decision making influenced by several aspects and, therefore, subject to training. Analyzing the flows in the choice of professionals for the use of physical restraint in the older adults living in an LTCF is necessary, since an in-depth analysis of the logical series of thought and actions' processing of professionals until decision-making can be a training strategy. In addition, their statements reveal that other types of restraint are used such as pharmacological, added to a concern for patient safety and the shortage of professionals, factors that may imply the decision for mechanical restraint.

\section{Category III: strategies to restrain and not}

The professionals and caregivers highlighted in their speeches the tacit knowledge of restraint strategies, mentioning the possibility of applying it safely: 
That's what I just said, if you don't do the restraint correctly, a disoriented patient can be injured. Especially in upper and lower limbs. Example: they may be hitting the bed rail and, with this movement, cause injury to themselves. If you put a bandage on them, they will immediately be forcing it to remove it. What can we do? Using pads, especially compress, several compresses, makes a very soft pad, so the patient is not injured at any time. We are always watching [...], all the time (Nursing technician I1).

"In Parachute restraint, the restraint goes from a bed rail to the other side of the bed, where it is attached to the other rail" (Nurse I2).

There are also records of alternatives of restraint, such as therapeutic communication, distraction techniques and encouraging of mobility:

Now, I don't think it's okay to put them in a room, I hate that they are tied up and medicated to be paralyzed. Everyone wants to put a bandage [...], I don't like that! They have to live! They're alive, they have to live! They need to participate in everything. If they want to talk, let them talk. Do you understand? (Caregiver I1).

I work with strategies, I see the need and assess, for example, an older person who is aggressive at bath time, who likes to pinch, punch, gets agitated because someone is touching them. I will talk to them, explain the need for a bath, and wrap a warm towel around their hands and feet; just wrap, not tie. I keep saying "look how cool, how warm", and that makes them calm (Nursing Technician I2).

Here is a 97-year-old woman who has good mobility, walks well, without the help of any instrument, but she is at risk, right? What do I do to reduce the risk of falling? She likes to draw, to paint, so I put a sketchbook and gradually give her crayons, so she keeps painting and writing and just sits there (Caregiver).

There is a culture among the health team members that makes physical restraint an option to provide care, despite the evident search for accessory care methods so that restraint is tolerated, but there are not so many alternatives that encourage mobility of the older adults.

\section{DISCUSSION}

The paradox in the care provided to the older adults regarding mechanical restraint stands out in the results of our study. While the statements of health professionals show that they are aware of the harmful effects and risks of this practice (in category I), its use is justified as patient safety, their protection, as also reported in foreign studies. ${ }^{9}$

Restraint is not a care strategy or a therapeutic procedure indicated in the care to the older adults. It should be used exceptionally and in specific cases, when no other option to avoid damage or immediate harm is available, and mainly to control patients with behavioral disorders or motor agitation. ${ }^{10,11}$

The restriction to its use is such that the Federal Nursing Council (COFEN, in the Portuguese acronym) standardized its use, determining, among other measures, that the monitoring of the contained individual occurs hourly (Resolution no. 427/12 of COFEN). ${ }^{12}$ However, reports in category I of justifications for the use of restraint were based on the small number of professionals or the risk of falls, which, again, contradicts the understanding of COFEN, which expressly prohibits the use of restraint for "convenience of institution" (Article 3 of Resolution no. 427/12). Measures to prevent falls should be considered as long as they guarantee the dignity of the human being in the use of their civil and fundamental right: their freedom. ${ }^{3,13}$

The main damages reported by the participants and caused by restraint in older people were: the pressure exerted (laceration, abrasion, or compression); psychological damage including fear, humiliation, anger, heartbreak; and all the possible consequences of forced immobility, such as falls and hospitalization that professionals witness day by day, corroborating the literature. ${ }^{9,14}$

The paradox of the reports is the use of patient safety as a justification, in direct opposition to the adverse events caused by restraint, such as pressure injuries, friction injuries, increased agitation and aggression, immobility, urinary incontinence, emotional losses, and even strangulation and death. ${ }^{15}$

In this sense, the National Patient Safety Program, instituted by Ordinance No. 529/2013 of the Ministry of Health, determines the reduction of the risk of unnecessary physical and psychological damage to the patient. ${ }^{16}$ Thus, a reflection on the presumed security of restraining frail older people should be made, since it causes physical, moral, and ethical damage to them over a conduct that is incompatible with human rights and, therefore, with the principles of patient safety.

In category II, the decision of using restraint or adopting strategies to avoid it, were related to the formation/training and subjective aspects of health professionals involved, as well 
as to the insufficient number of professionals in the facility, structural inadequacy, or the use of drugs (pharmacological restraint). Systematic clinical decisions and care practices for the older adults are needed in the LTCF, with individualized assessment of cases, as well as the involvement and debate between the multidisciplinary team members. ${ }^{3,17}$

In this sense, we have contradictory reports of categories I and II, which point to the damages to the individual, such as the restriction of their freedom, but at the same time state that there is no other viable way out. It is important to highlight two points that seem to justify such contradictory statements: although professionals have a certain autonomy in their activities, their technique is limited by the institution itself. It has its own rules and management premises, determining, even by financial reasons, the number of professionals hired and, perhaps, what protocols to be adopted to exempt their managers from any events or accidents in the facilities. ${ }^{14}$

The statements seem to demonstrate the concern of the employees when it comes to the performance of their duties, as limitations of personnel are imposed on them and as they are to be blamed in the event of a fall. ${ }^{9}$ For this reason, some reports reflect the sadness of the nursing technician or nurse when they need to perform physical restraint, as they know its harmful effects. In addition, reports are homogenous despite the different realities of the LTCFs included in the study: a philanthropic and a private institution.

Regarding the strategies related to the decision of using or not restraint brought by category III, the need for constant training of professionals is emphasized. ${ }^{18}$ To that end, the World Health Organization (WHO) provides specific training with strategies to eliminate the restraint in care environments, which include, among others: the creation of a culture of care free from restraint (in which one says "yes" and "I can care for it"); and the identification of possible situations that bring insecurity, pain, anger, anguish, and that can generate violent or disturbing behaviors. The objective is to bring awareness to health professionals or caregivers about good care practices, free from restraint. ${ }^{19}$

The literature addresses the need for the team to examine the possible causes of agitation in the older adults, and the most commonly cited are: asymptomatic infections, iatrogenic drug events, environmental changes, dehydration and physiological needs. ${ }^{3,20}$ By attempting to identify them, the abuse of restraints can be reduced by itself. It is worth remembering that a professional or family member close to the older adults is the most qualified individual to recognize changes in mood, behavior, and non-verbal language in older people with cognitive complaints or special needs. ${ }^{3}$
Some alternatives to the use of restraint were also described in category III: environmental stimulation, increased frequency and length of visits, physical therapy to maintain muscle tone, the low bed or Alzheimer bed and/or mattress on the floor, among others, as reported in the foreign literature. ${ }^{21}$ However, there were also reports of restraint interventions that are not formalized in the literature, that is, improvised in daily life, such as the "parachute" technique, in which a person is subjected to serious adversities that may lead to death. ${ }^{7}$

Therefore, the approach and care of older people with neuropsychiatric symptoms is challenging and require more time and, above all, permanent technical-scientific training. Some continued strategies - that is, long-term, planned and personalized approach to each person, such as music, cognitive stimulation, socialization and physical activities - can reduce episodes of agitation and aggression, as well as prevent falls by maintaining physical and cognitive activities. ${ }^{22-24}$

A contention-free care decreases agitation and aggressiveness of individuals, ${ }^{4}$ enabling approaches by care professionals that maximize their functionality and encourage autonomy. It is the right of the older person, as a patient and a human being, to receive quality healthcare. This also means a service free of damages and injuries, which does not happen with the usual practice of mechanical restraint.

Some of the limitations of this study were the small number of LTCFs selected and their singularities, as well and the difficulty in verbalizing some questions or the discomfort shown by interviewees. As for the essence of qualitative approaches, it should be noted that they are based on specific inferences, which can suppress some important issues not encompassed in the analysis.

It is important to note that this is the only study conducted in Brazil, as only in foreign literature was it possible to describe the perception of health professionals about the use of restraint. And since not only nurses were interviewed, but also other health professionals, it enhances the research, given the inherent multidisciplinary character of care provided to the older adults. Further studies could comprise a larger number of LTCFs and professionals interviewed, so as to expand the diversity of the organizational cultures of LTCFs, perhaps establishing a triangulation of findings with those of the present study.

\section{CONCLUSION}

By describing professionals' perception of the use of mechanical restraint, we demonstrate that daily challenges in caring for older people with special needs due to behavioral 
disorders, with low infrastructure or little training aimed at long-term care can be overcome.

The need for training formal and informal caregivers to denaturalize the practice of restraint is highlighted, as it aggravates their health status both physically and mentally, and this cultural change must be promoted by society, health institutions, and teaching and research institutions.

The discussion on alternative practices to mechanical restraint should be broaden, encouraging rehabilitation practices, as these preserve the autonomy of the older adults and thus give them dignity, respecting gerontological principles.

\section{ACKNOWLEDGEMENTS}

In memory of Arianna Kassiadou Menezes, our eternal professor, who inspired and inspires us to study and take to the world the culture of care centered on the older adults and free from restraint. To her we give our eternal gratitude.

\section{CONFLICT OF INTERESTS}

The authors declare no conflict of interests.

\section{FUNDING}

None.

\section{AUTHORS' CONTRIBUTION}

RFS: conceptualization, formal analysis. MRSA: conceptualization, formal analysis. MBC: conceptualization, formal analysis. RDV: conceptualization, formal analysis. PFAB: conceptualization, formal analysis. ACSC: conceptualization, formal analysis.

\section{REFERENCES}

1. Fagundes KVDL, Esteves MR, Ribeiro JHM, Siepierski CT, Silva JV, Mentes MA. Instituições de longa permanência como alternativa no acolhimento das pessoas idosas. Rev Salud Pública [Internet]. 2017 [Accessed in Dec 20, 2019];19(2):210-4. Available in: https://doi. org/10.15446/rsap.v19n2.41541

2. Salcher EBG, Portella MR, Scortegagna HM. Cenários de instituições de longa permanência para idosos: retratos da realidade vivenciada por equipe multiprofissional. Rev Bras Geriatr Gerontol [Internet]. 2015 [Accessed in Apr. 23, 2019];18(2):259-72. Available in: http://www.scielo.br/scielo.php?script=sci_arttext\&pid=\$180998232015000200259\&lng=en http://dx.doi.org/10.1590/18099823.2015 .14073

3. Santana RF, Delvale R, Souza LMS, Menezes AK, Capeletto CSG, Ferreira TCB, et al. Contenção Mecânica em Instituições de Longa Permanência para Idosos. Rev Enferm UFPE [Internet]. 2018 [Accessed in Dec. 31, 2018];12(12):3394-400. Available in: https://periodicos.ufpe.br/ revistas/revistaenfermagem/article/view/234527/30815 https://doi. org/10.5205/1981-8963-v12i12a234527p3394-3400-2018

4. Oye C, Jacobsen FF, Mekki TE. Do organizational constraints explain the use of restraint? A comparative ethnographic study from three nursing homes in Norway. J Clin Nurs. 2017 [Accessed in Dec. 30, 2019];26(1314):1906-16. Available in: https://doi.org/10.1111/jocn.13504

5. Menezes AK, Santana RF, Cimador F. Práticas assistenciais restritivas e o paradigma da cultura de não contenção da pessoa idosa. In: Freitas EV, ed. Tratado de geriatria e gerontologia. $4^{a}$ ed. Rio de Janeiro: Guanabara Koogan; 2016. p. 6582-627.

6. Melo LA, Braga LC, Leite FPP, Bittar BF, Oséas JMF, Lima KC. Fatores associados à multimorbidade em idosos: uma revisão integrativa da literatura. Rev Bras Geriatr Gerontol [Internet]. 2019 [Accessed in Jan. 10, 2020];22(1):e180154. Available in: http://www.scielo.br/scielo. php?script=sci_arttext\&pid=S1809-98232019000100302\&lng=en

7. Berzlanovich AM, Schöpfer J, Keil W. Deaths due to physical restraint. Dtsch Arztebl Int. 2012 [Accessed in July 5, 2020];109(3):27-32. Available in: https://www.ncbi.nlm.nih.gov/pmc/articles/PMC3272587/

8. Leahy-Warren P, Varghese V, Day MR, Curtin M. Physical restraint: perceptions of nurse managers, registered nurses and healthcare assistants. Int Nurs Rev [Internet]. 2018 [Accessed in Jan. 23, 2020];65(3):327-35. Available in: https://doi.org/10.1111/inr.12434
9. Chapman R, Ogle KR, Martin C, Rahman A, McKenna B, Barnfield $\mathrm{J}$. Australian nurses' perceptions of the use of manual restraint in the Emergency Department: a qualitative perspective. J Clin Nurs. 2016;25(9-10):1273-81. https://doi.org/10.1111/jocn.13159

10. Pan Y, Jiang Z, Yuan C, Wang L, Zhang J, Zhou J, et al. Influence of physical restraint on delirium of adult patients in ICU: A nested case-control study. J Clin Nurs. 2018;27(9-10):1950-7. https://doi. org/10.1111/jocn.14334

11. Cimador F. A cultura da não contenção da pessoa idosa Uma necessidade, um direito e uma batalha ética e política. RevEnferm UFSM. 2017 [Accessed in Aug. 30, 2019];7(1):i-ii. Available in: https://triesteliberadacontenzione.files.wordpress. com/2017/07/universitc3a0-santa-maria.pdf https://doi. org/10.5902/21797692133370

12. Conselho Federal de Enfermagem (COFEN). Resolução no 427, de 7 de maio de 2012: Normatiza os procedimentos da enfermagem no emprego da contenção mecânica de pacientes [Internet]. Brasília: COFEN; 2012 [Accessed in July 5, 2020]. Available in: http://www. cofen.gov.br/resoluo-cofen-n-4272012_9146.html

13. Eskandari F, Abdullah KL, Zainal NZ, Wong LP. The effect of educational intervention on nurses' knowledge, attitude, intention, practice and incidence rate of physical restraint use. Nurse Educ Pract. 2018 [Accessed in Dec. 7, 2019];32:52-7. Available in: https://www. sciencedirect.com/science/article/pii/S147159531730272X?via\%3Dihub https://doi.org/10.1016/j.nepr.2018.07.007

14. Souza LMS, Santana RF, Capeletto CSG, Menezes AK, Delvalle R. Fatores associados à contenção mecânica no ambiente hospitalar: estudo transversal. Rev Esc Enferm USP [Internet]. 2019 [Accessed in June 14, 2019];53:e03473. Available in: http://dx.doi.org/10.1590/ s1980-220x2018007303473

15. Albuquerque A. A segurança do paciente à luz do referencial dos direitos humanos. Rev Direito Sanitário 2016;17(2):117-37. https:// doi.org/10.11606/issn.2316-9044.v17i2p117-137

16. Brasil. Ministério da Saúde. Portaria no 529/2013: Institui o Programa Nacional de Segurança do Paciente [Internet]. Brasília: Ministério da Saúde; 2013 [Accessed in Oct. 24, 2019]. Available in: http://bvsms saude.gov.br/bvs/saudelegis/gm/2013/prt0529_01_04_2013.html

17. Muñiz R, Gómez S, Curto D, Hernández R, Marco B, García P, et al. Reducing Physical Restraints in Nursing Homes: A Report From Maria Wolff 
and Sanitas. JAMDA. 2016;17(7):633-9. https://doi.org/10.1016/j. jamda.2016.03.011

18. Donato TAA, Pires LR, Silva LCP, Moura LVC, Santos AA, Souza LF. Physical restraint in patients in Intensive Care Units: exploratory - a descriptive study. Online Braz J Nurs [internet]. 2017 [Accessed in Oct. 20, 2019];16(1):83-93. Available in: http://www.objnursing.uff.br/ index.php/nursing/article/view/5562 https://doi.org/10.17665/16764285.20175562

19. World Health Organization. WHO Quality Rights Specialized training. Course guide [Internet]. Geneva: World Health Organization; 2019 [Accessed in Mar. 21, 2020]. Available in: https://www.who.int/ publications-detail/who-qualityrights-guidance-and-training-tools

20. Foebel AD, Onder G, Finne-Soveri H, Lukas A, Denkinger MD, Carfi A, et al. Physical restraint and antipsychotic medication use among nursing home residents with dementia. J Am Med Dir Assoc. 2016;17(2):184. e9-184.e14. https://doi.org/10.1016/j.jamda.2015.11.014

21. González EJ, Carbajo PM, Sirvent NV, García TC, González GJ, Pariente RE. Uso de contenciones en el anciano. La perspectiva de familiares y cuidadores. Rev Rol Enfermería [Internet]. 2017 [Accessed in Oct.
20, 2019];40(11-12):754-60. Available in: https://medes.com/ publication/127061

22. Perdigão LMNB, Almeida SC, Assis MG. Estratégias utilizadas por cuidadores informais frente aos sintomas neuropsiquiátricos de idosos com demência. Rev Ter Ocup Universidade São Paulo [Internet]. 2017 [Accessed in Jan., 2020];28(2):156-62. Available in: https://doi. org/10.11606/issn.2238-6149.v28i2p156-162

23. Dauwan M, Begemann MJH, Slot MIE, Lee EHM, Scheltens P, Sommer IEC. Physical exercise improves quality of life, depressive symptoms, and cognition across chronic brain disorders: a transdiagnostic systematic review and meta-analysis of randomized controlled trials. J Neurology [Internet]. 2019 [Accessed in Jan. $1^{\text {st }}$, 2020]. Available in: https://doi. org/10.1007/s00415-019-09493-9

24. Nascimento JS, Tavares DMS. Prevalência e Fatores Associados a quedas em idosos. Texto Contexto - Enferm [Internet]. 2016 [Accessed in Dec. 24, 2020];25(2):e0360015. Available in: https:// doi.org/10.1590/0104-07072016000360015 